\title{
СПЕЦИФИКА ИНЖЕНЕРНОЙ ПОДГОТОВКИ ВЫПУСКНИКОВ УНИВЕРСИТЕТА В СИСТЕМЕ МЕЖДУНАРОДНОГО ОБРАЗОВАНИЯ
}

\author{
Оринина Лариса Владимировна \\ к.П.н., доцент \\ ФГБОУ «МГТУ им. Г.И. Носова»
}

Аннотация. В данной главе научной монографии представлена попытка описания современной инженерной подготовки обучающихся, ее сущность, структура, функции, особенности реализации в структуре поликультурного образовательного пространства. Кроме того, в главе представлен материал о специфике реализации международных образовательных проектов, освещены некоторые методические аспекты в преподавания в системе современного международного образования, лучшие европейские практики, а также приведены стратегии формирования профессиональной траектории выпускников вуза. Кроме того, в главе представлены некоторые практические материалы по формированию готовности современного педагога к преподаванию инженерных дисциплин.

Ключевые слова: международные образовательные проекты, инженерная подготовка, современное образовательное пространство, поликультурная направленность, критическое мышление, стратегии карьерного роста выпускников, методика преподавания, обучающиеся.

\section{SPECIFICITY OF ENGINEERING TRAINING OF UNIVERSITY GRADUATES IN THE INTERNATIONAL EDUCATION SYSTEM}

\section{Orinina Larisa Vladimirovna}

Abstract: This chapter of the scientific monograph presents an attempt to describe foundations of modern engineering training of students, its essence, structure, functions, and implementation features in the structure of a multicultural educational space. In addition, the chapter of the monograph presents material on the specifics of the implementation of the international educational projects on the platform of the consortium universities, describes the technologies for the 
development of students' creative thinking, highlights some methodological aspects in teaching certain disciplines.

Key words: international educational projects, engineering training, modern educational space, multicultural orientation, critical thinking, teaching methods, students.

Актуальной и перспективной в условиях динамично развивающейся экономики является проблема разработки теоретико-методологических и практических оснований педагогического сопровождения и поддержки готовности обучающейся молодежи, в том числе и будущих рабочих кадров к профессиональной карьере; создания механизмов и технологий подготовки обучающихся на всех этапах обучения к жизненной и профессиональной карьере в ситуации непредсказуемости экономических перемен; выявления направлений оценки профориентационно значимых инициатив регионального, муниципального и локального уровня, практик корпоративной и отраслевой профессиональной ориентации; определения рисков редуцирования смыслов педагогического сопровождения становления субъекта профессионального самоопределения до удовлетворения кадровых потребностей субъектов экономики; организации взаимодействия образовательных организаций между собой и с внешними структурами государства, общества и бизнеса для достижения целей согласования ожиданий, потребностей и интересов социальных заказчиков с возможностями, склонностями и профессиональными намерениями обучающихся. Анализ социально-психологической и экономической литературы показал, что социальноэкономическими предпосылками формирования профессиональной готовности обучающихся инженерных направлений подготовки на всех возрастных этапах являются:

- системность профориентационной работы образовательных организаций, мотивирующей обучающихся к трудовой деятельности по профессиям и специальностям, востребованным на рынке труда;

- межведомственное взаимодействие в системе профориентации обучающихся;

- социальное партнёрство в проведении профориентационных мероприятий, направленных на социально-экономическую адаптацию молодёжи на рынке труда;

- гармонизация взаимосвязи профессионального, жизненного и личностного самоопределения, что позволяет выходить на проблематику формирования системы ценностей и поиска смысла профессионального труда и всей жизни, что 
делает профориентационную работу важным условием социализации личности и её гражданского становления. В выстраивании непрерывного образования для подготовки перспективных кадров должны прослеживаться этапы (периоды, шаги): предпрофильная подготовка и профильное обучение в школах; дополнительное образование, среднее и высшее (двухуровневое) профессиональное образование, различные формы повышения квалификации, целевая интенсивная подготовка специалистов по заказам работодателей. Основными противоречиями профессиональной ориентации, негативно влияющими на процесс профессионального самоопределения молодежи, в настоящий момент являются следующие:

- между потребностью государства и бизнеса в кадровом обеспечении в соответствии с динамичным запросом рынка труда и отсутствием государственного статуса (заказа на профессиональную ориентацию молодежи);

- между потребностями и ожиданиями старшеклассников в оказании им педагогической поддержки в профессиональном самоопределении и недостаточной готовностью педагогов, родителей и других социальных партнеров к решению данной проблемы;

- между необходимостью поддержки профессионального самоопределения подростков в условиях профилизации старшей школы и недостаточной разработанностью современных профориентационных средств, удовлетворяющих индивидуальные запросы школьников;

- между необходимостью обеспечения преемственности общего и профессионального образования; организации системы непрерывного образования и происходящими демографически-миграционными сдвигами, а также деформациями в структуре подготовки кадров, организации и содержания профессионального образования. Анализ сложившейся ситуации с профессиональным самоопределением будущих выпускников российских школ показывает, что как образовательно-кадровые проблемы, так и проблемы проектирования послешкольного будущего конкретными обучающимися находятся в зависимости от возможности разрешения ряда проблем, различающихся по масштабам рассмотрения и уровням управления:

- готовности к профессиональному самоопределению будущих выпускников общеобразовательных учреждений;

- компетентности педагогов в проведении профориентационной работы и оказании учащимся педагогической поддержки профессионального самоопределения; 
• отношений социальных партнеров общеобразовательных учреждений к участию в профориентационной деятельности школы;

- управления ресурсами профессиональной ориентации и педагогической поддержки профессионального самоопределения со стороны представителей региональной образовательной политики;

• нормативного и организационно-методического обеспечения профессиональной ориентации и педагогической поддержки профессионального самоопределения молодежи. Всё вышесказанное актуализирует необходимость новых подходов к профессиональному самоопределению учащейся молодёжи в условиях непрерывного образования с ориентацией на лучшие образовательные практики Европы и в соответствии с международными образовательными стандартами. В этой связи большую роль игрет система участия современных российских вузов в конкурсе международных образовательных проектов ERASMUS+. Международные проекты направлены не только на формирование активной жизненной позиции молодежи, на всестороннее развитие их личности, трансформацию «Я-концепции», повышение уровня как профессиональной, так и жизненной мотивации, а также на популяризацию и повышение престижа здорового образа жизни, формирование новой политики в сфере экономики, социокультурного развития, масс-медиа и общественнополитической жизни общества. Рассмотрим подробнее влияние международных образовательных проектов на трансформацию всех вышеперечисленных сфер.

С точки зрения гендерных особенностей международные проекты важны тем, что за счет реализации образовательных программ в международных центрах происходит гендерное «выравнивание», что позволяет избежать нежелательной для общества «гендерной асимметрии», при которой женщины современного общества традиционно более активны и более интенсивно осваивают социально значимые виды деятельности и считающиеся традиционно мужскими профессии. В данных проектах акцент сделан на инженерном образовании, что позволит привлечь в структуру проекта, а также последующее обучение в Центрах мужскую половину молодежи, в то время как девушки смогут более активно включиться в программы профессиональной переподготовки и повышения квалификации по гуманитарным направлениям подготовки. Кроме того, выезднгые семинары в рамках посещения вузов консорциума с целью обучения и международного обмена образовательными и научными сценариями также будет способствовать 
гендерной симметрии молодежи [2, с. 47].

С точки зрения наблюдающейся во всех странах, особенно среди молодежи, безработицы международные образовательные проекты является социально значимыми, так как позволяют создать в обществе определенный прецедент, направленный на повышение престижа как образования в целом, так и преемственности образовательной системы, в частности: в данном случае имеется в виду повышение рейтинга популярности среди молодежи обучения в аспирантуре. Участие в международных образовательных проектах является социально значимым событием, связанным с возможностью передать как социокультурный и научный опыт коллег, так и погрузиться в иную языковую среду, помогающую молодому человеку совершенствовать базовый уровень развития у него значимых общепрофессиональных, общекультурных и учебнопознавательных компетенций.

$\mathrm{C}$ точки зрения здравоохранения и пропаганды здорового образа жизни молодежи в международном образовании может быть реализован комплекс мероприятий, обращенных на:

-развитие новых форм социального партнерства муниципальных и общественных организаций, государственных структур и СМИ в интересах охраны здоровья населения и окружающей среды;

-ориентацию молодежи на содержательные виды организации досуга (спорт, творчество, туризм, добровольческая деятельность) через прямое информирование, Интернет и СМИ [3, с. 169].

С точки зрения общественных связей и развития глобальных масс-медиа международные образовательные проекты могут быть важны для потенциально эффективного паблик рилейшнз, а также возможности повысить рейтинг развития бренда университетов консорциума, например, в рамках проведения приемной кампании и процесса набора абитуриентов, в частности, на некоторые инженерные направления подготовки, пользующиеся традиционно невысоким спросом среди абитуриентов (например «Взрывное дело», «Горные машины и оборудование» и т. д.

Проекты в области развития потенциала высшего образования - это проекты межинституционального сотрудничества университетов стран Программы и стран-партнёров с участием при необходимости не академических партнеров, направленные на:

- модернизацию, расширение доступности и развитие интернационализации высшего образования в странах-партнерах; 
- создание платформы для развития и укрепления сотрудничества между странами ЕС и странами-партнерами;

- содействие добровольному сближению с тенденциями развития высшего образования в странах ЕС;

- содействие межкультурному и межличностному обмену.

Наука сможет существенным образом прогрессировать, если вузам будет предоставлена возможность использования передовых европейских разработок в системе образования и инноваций для создания новейших образовательных платформ на базе вузов консорциума. Кроме того, система научных стажировок студентов и использование программ академической мобильности позволит существенным образом расширить спектр педагогических подходов и технологий, применение которых, несомненно, выведет вузы на качественно иной образовательный и научный уровни. Болонский процесс и Европейское пространство высшего образования положили начало реформам, направленным на улучшение инженерного образования как во всем мире, так и в некоторых странах. Несмотря на возрастающий интерес молодежи к инженерному образованию, оно до сих пор претерпевает целый ряд социальных и педагогических трансформаций [4, с. 288]. Одна из основных нерешенных проблем связана с ухудшением системы подготовки преподавательских кадров в университетах-партнерах и снижением эффективности используемых методов преподавания инженерных дисциплин в России. Поэтому международное образование сегодня направлено на изменение системы педагогической подготовки преподавателей университета по инженерным дисциплинам в России посредством модернизации программ аспирантуры, разработки устойчивой системы переподготовки преподавателей и их консультационной поддержки со стороны сети Центров Совершенства по инженерному образованию. Приоритетная цель международног образования - улучшение качества и эффективности преподавания. Обучающие программы для аспирантов и преподавателей университета по инженерным дисциплинам будут включать модуль для применения в инженерном образовании методик преподавания, основанных на информационно-коммуникационных технологиях (ИКТ).

Реализация международных образовательных проектов в итоге приведет:

- к освоению лучших европейских практик, а также образовательных практик России по подготовке преподавателей инженерных дисциплин;

- к повышению уровня сформированности информационно-коммуника 
тивной компетентности аспирантов и преподавателей в области преподавания инженерных дисциплин;

- к разработке и эксплуатации международных образовательных центров, включая разработку документации, набор и обучение персонала для этих центров;

- к заимствованию европейского опыта в области преподавания инженерных дисциплин преподавателями вузов и его трансформация применительно к образовательных условиях российских вузов

- к разработке и апробации учебного плана и методологии педагогической подготовки аспирантов и преподавателей вузов по инженерным дисциплинам;

- к подготовке и публикации статей, индексируемых в базах Web of Science и Scopus, монографии и методическое пособие, в которое будут включены обучающие методики по инженерным дисциплинам.

Основными задачами международных образовательных проектов на сегодняшний день являются следующие:

1) разработка комплексной модели и дескрипторов компетенций преподавателей университета по инженерным дисциплинам;

2) создание сети Центров Совершенства по инженерному образованию, способных обеспечить базу для исследований, обучающие курсы и консультационные услуги по преподаванию инженерных дисциплин в вузах стран-партнеров;

3) разработка обучающих программ для аспирантов и преподавателей университета по инженерным дисциплинам, включая массовые открытые онлайн-курсы. Современные международные проекты направлены на модернизацию подходов к преподаванию инженерных дисциплин в странахпартнерах, улучшение качества образования и трудоустройства молодых инженеров, повышение мотивации студентов и привлекательности инженерного образования в целом.

С.Л. Зарецкая считает, что «многие факторы способствуют усилению процессов интерна- ционализации образования. Сокращение государственного финансирования высшей школы в 90-е годы, финансовый кризис вузов многих стран усилили конкуренцию между вузами за привлечение иностранных студентов». Увеличение доходов вузов от платы за обучение иностранных студентов рассматривается руководителями вузов, а также правительствами (стимулирующими вузы активизировать деятельность по привлечению иностранных студентов, развитию дистанционного обучения, созданию 
виртуальных университетов) как один из способов решения финансовых проблем высшей школы. В 90-е годы во многих странах мира наблюдалось замедление темпов роста государственной поддержки высшей школы, в некоторых странах в отдельные годы этого периода эта помощь в реальных ценах сокращалась. Государственное финансирование образования в большинстве промышленно развитых стран, считают западные эксперты, уже достигло предельно возможной величины, вряд ли можно ожидать дальнейшего его наращивания. В этих условиях особенно актуальными для высших учебных заведений становятся разработка и реализация различных методов адаптации к условиям ограниченности бюджетного финансирования, нехватка средств, выделяемых государством на высшее образование [1, с. 37].

По мнению западных ученых (MeriamSh., CaffarellaR., 1999), статус института образования взрослых обусловлен, прежде всего, социальноэкономическим развитием и претерпевает изменения в зависимости от этого развития. Социокультурный контекст создает для взрослых особые потребности и интересы в развитии. Кроме этого, во многих странах отмечаются демографические изменения. Наблюдается общая тенденция старения населения, что связано с более высокой экономической состоятельностью населения по сравнению с предшествующими поколениями. Также западные авторы пишут в своих работах об увеличении свободного времени у взрослых людей, что обусловлено развитием технического прогресса. В настоящее время образование взрослых развивается достаточно интенсивно в более чем 42-х странах Европы, о чем свидетельствует большое количество научных работ, монографий, статей, докладов и тезисов конференций в области непрерывного образования. Например, в Финляндии образование для взрослых реализуется в формальных и неформальных формах, а также - как либеральное образование, связанное с изучением иностранных языков, информационными технологиями, спортом и др. На рынке либерального образования осуществляют деятельность учебные ассоциации, поддерживаемые политическими партиями; культурные и религиозные организации; летние университеты; народные высшие школы; центры образования для взрослых; спортивные учебные центры; университетские центры непрерывного образования; музыкальные школы и др. В Финляндии применяется концепция «паспорта учебных достижений», в котором представлены все результаты непрерывного образования взрослого. По данным международных исследований, Швеция лидирует по количеству вовлеченных в сферу образования взрослых в возрасте от 16 до 65 лет (52,5\% 
населения), наряду с такими странами, как Великобритания (43,9\%), Нидерланды (37,4\%), Ирландия (24,3\%), Бельгия (21,2\%), Польша $(13,9 \%)$. В диссертационном исследовании Зотовой Т.П. «Использование шведского опыта образования взрослых в отечественной педагогической теории и практике» представлен опыт шведского «фолкбилднинг» (folkbildning) в рамках высших народных школ (означает народное образование, не связанное с получением официального документа о квалификации). Отличительной особенностью этих школ является практика разработки программ при участии слушателей курсов, с учетом профессионального и жизненного опыта контингента конкретной учебной группы. В Швеции уже более ста лет этой традиции - добровольного объединения людей в группы с целью посещения интересующих их лекций и занятий, участия в культурных мероприятиях [5, с. 234]. Практически в каждой стране существуют свои особенности существования системы «folkbildning» и высших народных школ. Схожи между собой системы образования взрослых в Швеции и Финляндии. Национальные особенности систем имеются в Дании, Норвегии и Исландии. В Германии функционируют различные формы образования для взрослых, которые представлены общим и профессиональным непрерывным академическим образованием. Общее образование направлено на общие образовательные потребности населения. Например, курсы для граждан старшего возраста, курсы для женщин. Профессиональное непрерывное академическое образование охватывает большее число возможных дисциплин. Продолжительность такого обучения может быть от нескольких дней до двух лет, в том числе - 30\% такого образования реализуется в дистанционной форме. Непрерывное образование направлено на обеспечение разнообразным группам населения возможности адаптироваться в изменяющемся мире. К тому же, возможно вовлечение в образовательный процесс мигрантов. Обеспечиваются такие потребности, как языковая подготовка, получение культурологических знаний, коммуникативных навыков и др. В работах Адама Смита, Альтфреда Маршала и др. отмечается, что расширение сферы образования в случае непрерывного образования взрослых можно воспринимать как инвестиции взрослых в свой интеллектуальный капитал. Правительства западных стран оказывают помощь в развитии разных форм дополнительного образования взрослых, понимая важность повышения квалификации рабочей силы и соответствия образовательного уровня населения прогрессивным изменениям в различных областях техники, производства, культуры в целом. Ответом на новые профессиональные потребности экономики явились специальные 
программы профессиональной подготовки и переподготовки взрослого населения.Тем не менее, анализ международных документов, публикаций российских и зарубежных исследователей, связанных с развитием системы образования взрослых в Европе, позволяет сделать вывод о существенных различиях в положении дел в данной сфере в отдельных странах. Институтом международного сотрудничества Немецкой ассоциации народных университетов совместно с Европейской ассоциацией образования взрослых (EAEA), отмечается, что «не во всех регионах Европы потенциал и важность образования взрослых получает надлежащее внимание», «различия в странахчленах ЕС до сих пор велики. В то время как в скандинавских странах, Ирландии и Нидерландах система образования взрослых граждан сложна и хорошо финансируется, в других странах данная система практически отсутствует». Международное сообщество обязалось изменить это положение путем реализации программы «Образование для всех», среди целей которой обеспечение полного удовлетворения образовательных потребностей взрослого населения. Однако результаты проведенного анализа теоретических и практических исследований свидетельствуют о наличии противоречий и вызовов, связанных с тем, что существующая система образования взрослых решает не все актуальные для современного общества профессиональные и личностные проблемы взрослых. Образование остается недоступным для многих социальных категорий населения. По данным международных исследователей, участие в программах образования для взрослых связано с уровнем базового формального образования. Высокий уровень первого образовательного опыта увеличивает потребность непрерывного образования до 4 раз, а в некоторых странах- до 10.

Внедренные в образовательную практику результаты подобных международных проектов в разных странах, и в России в том числе, оказывают как прямое, так и опосредованное влияние на качество преподавания в вузе. Прямое влияние заключается в модернизации используемых НПР педагогических подходов и технологий к организации обучения студентов: используются те подходы, которые наиболее эффективно зарекомендовали себя в европейской практике обоазования и соответствуют единой цели проектовсовершентствованию педагогических подзодов в системе инженерного образования [6, с. 358]. Опосредованное влияние связяно с разработкой дискрипторов компетенций, формируемых у студентов всех вузов консорциума в соответствии с общими целями и задачами проекта. Кроме того, качество 
обучения и преподавания способно претерпевать качественные изменения в связи с начавшейся разработкой программ учебных курсов, платформа для реализации которых будет создана в ближайшее время в каждом вузе. Внедренные результаты, несомненно, влияют и на систему менеджмента и управления вузом. Обогащение европейским опытом сотрудничества с ведущими вузами создает предпосылки для изменения и соаершенствования стратегий управления вузом, основанных на интеграции в систему управления передовых тенденций менеджмента в руководстве крупнейшими образовательными учреждениями, базирующихся на следующих принципах: принцип международной научной интеграции, принцип преемственности и другие.

Таким образом, на сегодняшний день инженерное образование в России связано с процессом формирования у выпускников инженерных направлений подготовки значимых профессиональных компетенций, необходимых для их профессионального самоопределения, высокого уровня экономической мобильности, ориентированной на лучшие европейские практики, предполагающие реализацию в образовательных системах проектного подхода, и предполагает не только высокую роль инноваций в современных образовательных системах, но и активное участие представителей молодежи в современных международных образовательных проектах, способствующих повышению их психолого-педагогической и научно-исследовательской культуры, необходимой для дальнейшей работе в университете.

\section{Примечания}

Глава монографии выполнена при финансовой поддержке гранта международного проекта Erasmus+ Capacity Building in Higher Education EXTEND586060-EPP-1-2017-1-RO-EPPKA2-CBHE-JP Excellence in Engineering Education through Teacher Training and New Pedagogic Approaches in Russia and Tajikistan»

\section{Список литературы}

1. Зарецкая С.Л. Международная составляющая современного высшего образования // Глобализация и образование. - М., 2001. - С. 38-74.

2. Оринина Л.В. Методические аспекты повышения психологопедагогической компетентности студентов // Вестник Магнитогорского государственного технического университета им. Носова. -2005. - № 6. C. 45-50. 
3. Оринина Л.В., Кашуба М.Г., Гафаров Ф.А. Современные педагогические подходы в системе инженерного образования России и Таджикистана. Вестник Таджикского национального университета. -2020. - № 1. - C. 169-176.

4. Оринина Л.В., Гафаров Ф.А. Методические аспекты процесса формирования экономического патриотизма у студентов вузов России и Таджикистана. В сб.: Актуальные проблемы современной науки, техники и образования. Тезисы докладов 77-й международной научно-технической конференции. -2019.- С. 288-289.

5. Романова, Е.П. Романов, И.В. Самарокова// Проблемы современного педагогического образования. - 2018. - № 60. - С. 233-236.

6. Романова М.В. Актуализация потребности самовозвышения в культуре научно - педагогического творчества/ М.В. Романова, Е.П. Романов, И.В. Самарокова // Проблемы современного педагогического образования. - 2018.№ 60. - С. 356- 360 .

(C) Л.В. Оринина, 2021 